\title{
A Study of English Conundrums' Setting and Solving from the Perspective of Relevance Theory
}

\author{
Tian Dong, Rui-hong Yin \\ English Department, North China Electric Power University, Baoding, China \\ Email address: \\ yuyanxue110@163.com (Tian Dong),2542095138@qq.com (Rui-hong Yin)
}

To cite this article:

Tian Dong, Rui-hong Yin. A Study of English Conundrums' Setting and Solving from the Perspective of Relevance Theory. Humanities and Social Sciences. Vol. 4, No. 4, 2016, pp. 106-112. doi: 10.11648/j.hss.20160404.14

Received: June 10, 2016; Accepted: July 2, 2016; Published: July 7, 2016

\begin{abstract}
English conundrums, as an important form of English riddles, are very interesting and bring entertainment to people's daily life. For its vivid form, specific purpose, and well-designed content, English conundrums raise researching interests among more and more scholars. These studies range from anthropology, folklore to rhetoric. In the recent decades, many scholars have also begun to explore them from linguistic perspectives. This paper tries to analyze English conundrums under the guidance of Relevance Theory, aiming to explain the dynamical process of setting and solving of English conundrums. After an intensive study, the author finds that principles of relevance, the cognitive context and the non-demonstrative inference are powerful for explaining the setting and solving of English conundrums.
\end{abstract}

Keywords: Relevance Theory, English Conundrums, Setting and Solving

\section{Introduction}

English conundrum is a special and interesting form of speech communication, and can bring entertainment and laughter to human daily life and activate human's thinking. They are so common and important in our daily entertainment life that many scholars such as anthropologists and folklorists have been attracted by this special language phenomenon. In recent years, some linguistic scholars have also begun to study English conundrums from different fields such as semantics, pragmatics and cognitive linguistics. Based on previous studies and the author's own understanding, this paper tries to analyze English conundrums from the perspective of Relevance Theory.

In the process of analysis, the author firstly collects data from different sources and then uses relative aspects of Relevance Theory to analyze them. Owing to the limits of time and words, the paper just chooses some representative examples to illustrate the application of Relevance Theory in the setting and solving of English conundrums.

Apart from introduction and conclusion, this paper altogether contains three parts. Part two is the literature review. In this part, the definition, features and previous studies of English conundrums are introduced. Part three is a brief introduction of some main points of Relevance Theory, including ostensive-inferential communication, two principles of Relevance and cognitive context. Part four is the core of the paper, making a detailed analysis of English conundrums. At first, source and collection of linguistic data are introduced. And then, based on Relevance Theory, a deep analysis of the setting and solving of English conundrums are respectively presented.

\section{Literature Review}

In 1956, the Oxford English dictionary gave "conundrum" the definition as "a pun or word-play depending on similarity of sound in words of different meaning". From then, most dictionaries define it depending on pun, so such definitions are usually regarded as the narrow sense. However, there are many conundrums don't include a pun. Wang Rongpei gave a much broader sense of conundrums. He held that the shrewd and witty questions in English should also be seen as conundrums [1]. This paper will adopt the broad sense of conundrums.

English conundrums, as a special language pattern, have their own characteristics. Liyuan mentioned that the crucial characteristic of conundrums is that "they are propounded not to seek information but for other purposes, such as fun-making and amusement [2]". Generally speaking, there 
are four main features of English conundrums. Firstly, a conundrum is usually made up of two parts: the question and the answer. In this thesis, the author names the person who puts forward the question as "riddler" and the person who answers the question as "riddlee". Secondly, the question is usually a brief wh-question and uses items like: why, when, where, what, whose, which, how and etc. Thirdly, the answer is always contrary to expectation but indeed reasonable, and it is likely to be given by the riddlers rather than the riddlees. Fourthly, there are usually two or more possible solutions, but only one is absolutely correct and can achieve entertainment.

English conundrums and riddles are very common and interesting language phenomenon. There are lots of scholars who have been attracted by their distinctively glamour. They explored them from different aspects such as folklore, anthropology and linguistics. Archer Taylor, a most excellent folklorist and anthropologist, wrote three works about his study of riddles and made a comparison between English riddles and those from other countries [3]. Bryant, another representative scholar, mainly described the history of English riddles [4].

Apart from many studies at abroad, there are also some scholars in China who have began to study the English riddles and conundrums. Wang Rongpei compared the Chinese "Miyu" and English riddles. He found that there are many similar features between them but he believed that there is no equivalence of Chinese lantern riddles in English. Besides, there are also other scholars engaged in the collection of English riddles such as Chen Xiru and Liu Kaifu. In addition, some Chinese scholars have tried to explore them from linguistic views.

Although all of the previous studies have made lots of contributions to the study of English conundrums, there are still limitations. Early studies from perspectives of anthropology, folklore and rhetoric just focus on the history and culture of English conundrums. They failed to interpret the internal mechanism of English conundrums and neglect the explanation of how a conundrum is produced. Considering this, the author intends to study English conundrums from the perspective of Relevance Theory, aiming to reveal some skills of designation and solution of the English conundrums through a dynamic analysis of the process of setting and solving.

In 1986, on the basis of criticizing and developing Grice's Cooperative Implicature, Sperber and Wilson put forward the Relevance Theory in their book: Relevance: Communication and Cognition. Relevance Theory is a combination of cognition and pragmatics; it intends to interpret language in terms of language psychology, cognitive psychology and communicative theory. Relevance Theory holds that there are no cooperative principles in the utterance communication and every thing is dominated by the "relevance". Sperber and Wilson creatively proposed some novel notions on the foundation of previous researches and their own studies. They are mainly as follows: ostensive-inferential communion, principles of relevance, maximal and optimal relevance and cognitive context. Relevance Theory provided a new sight for explaining language phenomenon such as humor, pun and irony.

In China, there are also scholars using this theory to analyze conundrums of both Chinese and English. Zhao Yijun studied the conundrums from the perspective of Relevance Theory. He mainly illustrated the non-demonstrate inference's application during the process of solving conundrums [5]. Jiang Bingqing and Liuyan also used the Relevance theory to analyze the conundrums. They mainly explained the function of cognitive context and the gap between maximal relevance and optimal relevance in the setting of conundrums [6]. Zhang Yushang, Ou Mingxu and Wang Weiping used the cognitive principle and communicative principle for illustrating the inferential process of English conundrums [7]. All above mentioned studies analyzed the conundrums just from one or two aspects of Relevance Theory or just analyzed the questioning or the answering of conundrums. This paper is going to make a more complete analysis of English conundrums from the perspectives of Relevance Theory.

\section{Key Notions of Relevance Theory}

Relevance Theory intends to study language communication from a cognitive point of view. This theory presents a new way of studying language phenomenon. It has been widely used to analyze various language phenomena such as humor, verbal irony, puns and so on. This thesis selects this theory as framework to analyze the English conundrums.

\subsection{Ostensive-Inferential Communication}

Traditionally, there are two models of verbal communication: code model and inferential model. According to code model, communication is achieved by encoding and decoding messages while inferential model holds that communication is achieved by producing and interpreting evidence. Combining code model and inferential model, Sperber and Wilson proposed a new model of communication-ostensive-inferential model. In their work Relevance: Communication and Cognitive, they defined ostensive-inferential communication as follows: "The communication produces a stimulus which makes it mutually manifest to communicator and audience that the communicator intends, by means of this stimulus, to make manifest or more manifest to the audience a set of assumptions I [8]." According to Sperber and Wilson, ostensive and inference are two parts of the same process. From the perspective of communicator, it is an ostensive process that gives audience stimulus of the communicator. From the audience, communication is the inferential process, in which the audience infers the intention from the stimulus. In addition, the ostension provides two layers of information: informative intention and communicative intention. The former refers that the speaker hopes to convey some information and the latter refers that the speaker expects that 
the hearer can recognize his informative intention. "Communication succeeds only when not only the communicative intention but the informative intention are recognized and fulfilled [9]".

\subsection{Principles of Relevance}

According to Sperber and Wilson, communication is dominated by "relevance". They defined relevance from two aspects: contextual effects and processing effort. It was defined as follows:

Extent condition 1: an assumption is relevant in a context to the extent that its contextual effects in this context are large.

Extent condition 2: an assumption is relevant in a context to the extant that effort required to process it in this context is small. (125)

Relevance is defined depending on two factors therefore it is not stable but has of different degree. Generally speaking, other things being equal the greater the contextual effects, the greater the relevance; the small the process effort, the greater the relevance. The maximal relevance refers to achieving the greatest contextual effect at the cost of the least efforts. However, in daily communication, speakers don't always offer the maximal relevant utterance; they like to express their thoughts indirectly. To understand such utterances, the hearer needs to choose the optimal one from a set of assumptions. Thus Sperber and Wilson put forward principle of relevance "Every act of ostensive communication communicates a presumption of its own optimal relevance" (158).

Sperber and Wilson hold that people always try to earn the greatest contextual effect with the least efforts in the cognitive process, but in the verbal communication activity, what people expect to obtain eventually is the optimal contextual effects. Hence, in the second edition, they revise their former principle of relevance into two principles: the cognitive principle and the communicative principle. They are defined respectively as follows:

The cognitive principle: Human cognition tends to be geared to the maximization of relevance.

The communicative principle: Every act of ostensive communications communicates a presumption of its own optimal relevance. (260)

For distinguishing maximal relevance and optimal relevance, He Ziran and Ran Yongping gave their views "the maximal relevance means in the interpretation of discourse, getting the greatest contextual effects for the smallest possible effort; the optimal relevance means in the interpretation of discourse, getting adequate contextual effects for efficient effort [10]".

\subsection{Cognitive Context}

Traditionally, context is regarded as a given one and is determined before an utterance. While Sperber and Wilson consider context as a psychological construct, a subset of assumptions that the hearer has retrieved after hearing the utterance. In Relevance Theory, context is fluid notion and continually replenished and extended. Sperber and Wilson regard the context as the following description:

"The context for the comprehension of an utterance consists of the assumption expressed and implicated by preceding utterance, plus the encyclopedia entries attached to any concepts used in these assumptions and in the utterance itself, plus the encyclopedia entries attached to any concepts used in the assumptions contained in the encyclopedia entries already added to the context" (136).

The context is defined in terms of the human cognition, so it is also called cognitive context by Sperber and Wilson. There are three kinds of information in the cognitive environment: logical, encyclopedia and lexical information. Besides Sperber and Wilson hold that the context is also influenced by religious belief, general culture assumptions, memories, expectation about the future and so on.

Cognitive context is not given but a matter of choice, and the selection of a particular context is determined by the search for relevance. For understanding an utterance, the hearer constructs a set of assumptions and selects the right contextual assumptions. That whether the hearer can select a correct context can directly influence the interpretation of the utterance. In other words, in order to understand the speaker's communicative information, the hearer needs to constantly extend the cognitive context in the process of pursuing the optimal relevance

\section{An Analysis of English Conundrums Based on Relevance Theory}

Since the English conundrums are interesting and Relevance Theory is a very convincing pragmatic theory, the author tries to analyze the English conundrums' setting and solving from the perspective of the Relevance Theory.

Most of the conundrums studied in the paper are chosen from Harry Collis's work named American English Riddles and Liu Kaifu's book called Collections of Interesting English Riddles [9], and examples are also selected from works of Feng Yufang, Chen Xiru and Weiguo. In order to make the study more persuasive, the author also selects examples from the internet or some English magazines.

\subsection{The Setting of English Conundrums}

English conundrums are not only interesting but also rich in wisdom. They bring much entertainment to people's daily life. But it is not easy to devise them. The author uses Relevance Theory to analyze their setting, aiming to let readers know them better.

\subsubsection{Taking Advantage of the Cognitive Principle}

Sperber and Wilson hold that "cognitive principle is that human cognition tends to be geared to the maximization of relevance" (260). They think that "cognitive resources tend to be allocated to the processing of the most relevant inputs available, whether from internal or external sources" (261). 
That is to say, in understanding an utterance, people tend to choose things or assumptions which have the maximal relevance to the utterance and context. For example, when the word "trees" is heard, plants which are tall and have a hard trunk, brunches, and leaves would come to our mind. "Christmas trees" or "plastic trees" would rarely be thought about even though they are also kinds of trees. Some English conundrums are designed by taking advantage of the cognitive principle. For example:

(1) What kind of pool you can't swim in?

Car pool

In (1), hearing the word "pool", people usually think of a small body of water in which they can swim. This is human's cognitive orientation. In daily life, people seldom think that it can also refer to a common supply of something. When people drive together in the same car so as to save gas and money, it's called a car pool. Obviously, it can't be used to swim but it is indeed a kind of pool. So some English conundrums select things that people seldom think about to set the question.

\subsubsection{Using the Dynamic Property of the Cognitive Context}

In Relevance Theory, "a context is a psychological construct, a subset of the addressee's assumptions about the world". It is not only influenced by logical information, encyclopedic knowledge and lexical information but also by religious belief, general culture assumptions, and memories and so on. "Traditional view of context is constant, fixed and static, while Relevance Theory view of context is variable and dynamic". It is not consolidated but changing and constantly reconstructed during a communication. Using dynamic context is also usual in the setting of the English conundrums. Look at the following examples:

(2) It usually takes 8 hours to travel from New York to Chicago by train. Then why hasn't the train leaving the New York more than 10 hours ago arrived yet?

The train was not for Chicago.

In (2) the riddler firstly sets a context in the question that "it usually takes 8 hours to travel from New York to Chicago". He deliberately makes the riddlee fall into this context and seeks the answer among the context. If the riddlee falls into the trap, he would likely fail to find the right answer. Such English conundrums are usually designed through using this skill. The riddlers deliberately change contexts between the question and the answer so as to trick people.

Besides, there is another kind of English conundrums which are designed by using this skill. Different from the above example, this kind of English conundrum doesn't give a certain context firstly but changes contexts through using puns either in the question or the answer. Let's look at an example:

(3) What word starts with "E" and ends with "E" but only has one letter in it?

Envelope

In this example, the change of contexts is realized by the word "letter". The word has different meanings in different contexts. One is "a written or printed sign representing a sound used in speech", the other is "a message that is written down or printed on paper and then usually put in envelops and sent to somebody". Apparently, the question adopts the first meaning and the answer adopts the second meaning. The riddler puts the "word" and the "letter" together on purpose and thus brings the riddlee to a context in which their most attention is paid to the first meaning. However, the context in which the second meaning used is totally different. The riddle skillfully transfers contexts by using puns to gain entertainment. Similar examples are shown in the following:

(4) What's the poorest bank in the world?

The river bank.

(5) What month do soldiers hate?

March.

\subsubsection{Pretending to Obey the Optimal Relevance Principle}

Simply speaking, an optimal relevance principle is one that makes your utterance relevant enough to arouse the addressee's attention and is also the most relevant one that the communicator can use to understand the utterance. In English conundrums, however, the riddlers always pretend to obey optimal relevance principle and make the riddlees believe that they do obey. In fact, the information they offer is usually the maximal relevant one but not the optimal relevance. There is always a gap between the maximal relevance and the optimal relevance. The bigger the gap is, the more difficult the conundrum is. For example:

(6) If a rooster laid an egg on top of a pointed-roof hen house, which side would the egg roll off?

Neither, because a rooster can't lay eggs

In the question, the riddler gives two choices "left side" and "right side". Obviously, they are the maximal relevant information that the riddlee will first pay attention to and make a choice between them. However, both the two choices aren't right answers in that it is a trap that the riddler deliberately designed. The riddler pretends to observe the optimal relevance principle and misleads the riddlee to believe that the maximal relevant information offered is the optimal relevance. Thus the intention of tricking people is fulfilled. The following are more examples:

(7) Is it better to write your homework on a full stomach or on an empty one?

It's better to write it on your exercise book.

Similarly, in (7) the riddler offers two choices and hopes that the riddlee would select one of them and get trapped.

Moreover, there is also another kind of conundrums which are made in this way. In those conundrums, the information given in the question is so adequate that the hearer will be caught easily. For such conundrums, the riddler pretends to follow the optimal relevance principle and gives much information which attracts the riddlee's attention. This information seems very reasonable and useful and has the maximal relevance to the question but it is not the optimal relevance. For example:

(8) At 6 O'clock in the morning a train leaves London for Edinburg and travels at the rate of 70 miles an hour. At the 
same time, another train starts from Edinburgh for London at the rate of 55 miles an hour. Which of the trains will be nearer to London when they meet?

They are at the same distance from London because they meet at London.

In this example, the riddler gives lots of information such as trains' rate and departure time, all of which are so reasonable that the riddlee has no excuse not to take advantage of the information. The riddler convinces the riddlee that he is obeying the optimal relevance principle and misleads the riddlee to consider the maximal relevance as the optimal relevance. If the riddlee did, he would never find the right answer. Once the answer is given, the entertainment effect could be fulfilled.

In a word, in such kind of English conundrums, the riddlers pretend that they obey the optimal relevance principle and deliberately make a gap between the maximal relevance and the optimal relevance. Generally speaking, the bigger the gap is, the more difficult the conundrum is and the more efforts to seek the right answer are.

To sum up, the above discussion involves three skills of English conundrums' setting: taking advantage of cognitive principle, using cognitive context and pretending to obey optimal relevance principle. No matter which skill the ridders use, the purpose is tricking the riddlees and getting the entertainment effect.

\subsection{The Solving of English Conundrums}

Some features of English conundrums have already been discussed. One of them is that the answer, at the most time, is given by the riddlers and thus the riddlers' intention of tricking people is fulfilled and entertainment effect generated. However, people are always eager to seek the right answer and once he gets it, he will gain a sense of achievement. In this section, based on Relevance Theory, some ways will be given to help the riddlees to find the right answer.

\subsubsection{Pursuing the Optimal Relevance}

In previous section, the last skill of English conundrums' setting is that the riddlers pretend to obey the optimal relevance principle and deliberately set a gap between the maximal relevance and the optimal relevance. For dealing with such conundrums, the riddlees should jump out of the gap to find the optimal relevance and get the right solution. Firstly, the riddlees should ignore the maximal relevance. Then they can use the encyclopedic knowledge or general knowledge to find the optimal relevance. For example:

(9) It usually takes a man two days to travel from San Francisco to New York by car. But Mr. Black left San Francisco on Friday and arrives on the same day. How could he do it?

He took a plane

In this example, the riddler gives the maximal relevant information such as "two days, travel, by cars" which are so highlighted that can catch the riddlee's attention firstly. But the riddlee should remember that it is a conundrum, so in order to find the right solution of the conundrum, he has to ignore the maximal relevant information and then just think about the question "how to arrive at New York from San Francisco on the same day?" In fact, there are three ways of transportations, passengers can not only drive a car but also can take a plane or a ship. In this way, using encyclopedic knowledge, it will be very easy to find the right answer-take a plane. Let's look at another example:

(10) If you stand with your back to the north and face south, what would be on your left hand?

Fingers.

In (10) the same skill can be applied. The information given in the question "If you stand with your back to the north and face south" is the maximal relevance. The riddler makes the riddlee believe that the information is useful for seeking the answer. Apparently, if he does, he will fall into the trap and can't find the right answer. In order to find the right solution, the riddlee should firstly neglect the maximal relevant information and then just think about what is on your left hand. Thought in this way, the question becomes so easy. The correct answer - fingers will be got

In a word, for dealing with this kind of English conundrums, the riddlees need to neglect the maximal relevance and make more efforts for the optimal relevance, and in most of the time, the optimal relevance comes from the common knowledge or daily experience.

\subsubsection{Extending the Cognitive Context}

Based on Relevance Theory, the context is not static but dynamic. In previous section, the author has already introduced that the riddlers take advantage of dynamic context to frame English conundrums. For dealing with such kind of conundrums, the riddlees need to break continually the pre-existing context and extending cognitive context until the right answer is found. Let's look at the following example:

(11) If six children and two dogs were under just one umbrella, how come none of them got wet?

It wasn't raining.

When hearing the question, the riddlee might firstly understand it from the literal meaning and get assumption A: It was raining. If the riddlee just stops at this level, he will not get the right answer. So the context needs to be extended continually. When he recognizes that none of them gets wet, he can take advantage of logical knowledge and encyclopedic knowledge to expend his cognitive context and revises the assumption A to B: holding an umbrella is not certainly in a raining day and then he can get the right answer-it wasn't raining. Here is another example:

(12) Lucky mouse fell off a 1000-step stair and was not hurt, why?

It fell of from the last step.

The pun-based conundrums are devised through transferring a word's meaning between two different contexts. Generally speaking, the questions made use of one contextual meaning and in the answers the other context is actually applied. For this kind of conundrums, the riddlees should change contexts during the process of thinking. For example: 
(13) Can anyone be safe if a man-eating lion is at large? Women and girls.

In this example, "man-eating" is generally understood as "human-eating". If so, it will be impossible for anyone to be safe. And this is a conundrum, so the answer can't be simple as "yes" or "no". For seeking the right answer, the riddlee should change the context and think about another contextual meaning of "man"-a human being who is both a male and an adult. Once this notion comes to the riddlee's mind, the answer will rise to the surface immediately. Apart from man- a male adult, there are still women and girls.

All in all, for dealing with this kind of English conundrums, the riddlees should constantly chang and extend their cognitive context and pursue new ideas in a new context and finally find the most appropriate answer.

\subsubsection{Using the Non-demonstrative Inference}

Although English conundrums are a special pattern of speech communication, they are still an utterance between the riddlers and riddlees. According to Relevance Theory, conundrums are a kind of ostensive-inference communication. In Relevance Theory, non-demonstration is a main pattern in the process of inference. The process can be simply summarized as "understanding the literal meaning - calculating the implicated premise-drawing a implicated conclusion". Because of the special characteristics of English conundrums, sometimes only one inference process is not enough and need to get another implicated premise from the implicated conclusion and then reach another implicated conclusion. Look at the following example:

(14) What animal is rich?

Bloodhound, because he is always picking up scent (cent).

When hearing this question, from the literal meaning, the riddlee could come into an implicated premise 1: What animal has lots of money? However, only human can own money. In this case, the riddlee needs to think about the different forms of money such as cent and dollar, and then could get the implicated conclusion 1: What animal has lots of cents or dollars? Then thinking about the key words "animal-cent" in the question, if so, it is not difficult for riddlers to associate the "animal-scent". Thus, the riddlee could draw an implicated premise 2: What animal has lots of scent. In this case, it is easy to reach the implicated conclusion 2: Bloodhound is always picking up scent. Finally, the correct answer - bloodhound comes into the surface. The interpretation of the following examples is the same as in

(15) Which is the strongest day of the week?

Sunday. Because the rest are week (weak) days.

To sum up, this part provides three ways to seek the right answers of English conundrums. They are: pursuing the optimal relevance, extending the cognitive context and using the non-demonstrative inference. For pursuing the optimal relevance, riddlees should jump out of the gap between maximal and optimal relevance. For extending the cognitive context, riddlees should use their general or existent knowledge to enlarge the dynamic context until they get the appropriate one. For using non-demonstrative, riddlees should get the implicated premise first and then get the implicated conclusion

\section{Conclusion}

English conundrums, as a form of English riddles, have been studied from many perspectives. This paper has tried to research them from the perspective of Relevance Theory, aiming to find setting and solving skills of English conundrums. It has found that three principles are used in the setting of English conundrums: taking advantage of the cognitive principle, using the dynamic property of cognitive context and pretending to obey the optimal relevance principle. As for taking advantage of cognitive principle, the riddlers use common things that people usually think as given information and use marginal and unusual things as the answer. In case of using the cognitive context, the riddlers tactfully change contexts between the question and the answer. In the case of pretending to obey optimal relevance principle, the riddler provides information which is very sensible and has maximal relevance and thus misleads the riddlees regard the information as optimal relevance.

When it comes to the solving skills of English conundrums, firstly, the riddlees should ignore the maximal relevance and jump out of the gap between the maximal relevance and the optimal relevance and make more efforts for seeking the optimal relevance. Secondly, for dealing with dynamic context-based English conundrums, the riddlees should continually extend their cognitive context. Thirdly, for some English conundrums, non-demonstrative inference plays a significant role in the process of seeking answers. The process can be simply presented as "understanding the literal meaning - calculating the implicated premise - drawing an implicated conclusion" and sometimes two or more circles are needed.

Although the present study made an effort to analyze the English conundrums based on Relevance Theory, some limitations still exist. Firstly, owing to the limitations of time and space, only some of the collected data have been taken as examples. Secondly, all the examples discussed in the present paper are analyzed by the author alone, so subjectivity is unavoidable. Thirdly, Relevance Theory is not perfect. Sperber and Wilson also acknowledge that Relevance Theory has its own limitations, so it is necessary to make further studies about English conundrums under the guidance of the Relevance Theory.

In spite of the limitations, the present study does make an effort to provide a new approach to study English conundrums. The Relevance Theory can also be applied to the analysis of Chinese brain-twisters and those similar language phenomena. Finally, the author hopes that the study in the paper would inspire more studies of English conundrum from other new views. 


\section{References}

[1] R. P. Wang, English Riddle Highlights, Dalian: Dalian University of Technology Press, 1999.

[2] Y. Li, "A semantic study of English conundrums," Jilin University, 2006.

[3] A. Taylor, English Riddles from Oral Tradition. Berkeley, CA: University of California Press, 1951.

[4] M. Bryant, Riddles Ancient and Modern. Hutchinson Publishing House, 1983.

[5] Y. J. Zhao, "Relevance theory to interpret brain teasers Settings and solution," J. Journal of Henan university of science and technology.

[6] B. Q. Jiang and Y. Liu, "Interpretation about Brain-twisters in the Perspective of Relevance Theory," J. Journal of Hunan Institute of Humanities, Science and Technology, 2010.

[7] Y. S. Zhang, M. X. Ou and W. P. Wang, "An exploration of English conundrum in the perspective of relevance theory" J. Journal of Mudanjiang University, 2012.

[8] D. Sperber, D. Wilson, Relevance: Communication and Cognition (2 ${ }^{\text {nd }}$ ed.). Oxford: Blackwell, 2001, pp. 63-260.

[9] X. R. Chen, A New Coursebook in Pragmatics. Beijing: Foreign Language Teaching and Research Press, 2009, pp. 150 .

[10] Z. R. He, Y. P. Ran, The basics of cognitive pragmatics-Relevance Theory. J. Modern Chinese Language, 1998. 